\title{
Main group mechanochemistry
}

\author{
Agota A. Gečiauskaitė and Felipe García*
}

\author{
Review \\ Address: \\ Division of Chemistry and Biological Chemistry, School of Physical \\ and Mathematical Sciences, 21 Nanyang Link, 637371, Singapore \\ Email: \\ Felipe García* - fgarcia@ntu.edu.sg \\ ${ }^{*}$ Corresponding author \\ Keywords: \\ ball milling; main group; mechanochemical synthesis; \\ mechanochemistry
}

\author{
Beilstein J. Org. Chem. 2017, 13, 2068-2077. \\ doi:10.3762/bjoc. 13.204 \\ Received: 15 May 2017 \\ Accepted: 08 September 2017 \\ Published: 05 October 2017 \\ This article is part of the Thematic Series "Mechanochemistry". \\ Guest Editor: J. G. Hernández \\ (c) 2017 Gečiauskaitè and García; licensee Beilstein-Institut. \\ License and terms: see end of document.
}

\begin{abstract}
Over the past decade, mechanochemistry has emerged as a powerful methodology in the search for sustainable alternatives to conventional solvent-based synthetic routes. Mechanochemistry has already been successfully applied to the synthesis of active pharmaceutical ingredients (APIs), organic compounds, metal oxides, coordination compounds and organometallic complexes. In the main group arena, examples of synthetic mechanochemical methodologies, whilst still relatively sporadic, are on the rise. This short review provides an overview of recent advances and achievements in this area that further validate mechanochemistry as a credible alternative to solution-based methods for the synthesis of main group compounds and frameworks.
\end{abstract}

\section{Introduction}

The original mainspring for the current expansion of solid state methodologies is the need for cleaner, safer and sustainable chemical transformations - particularly since raw materials are becoming ever scarcer. A straightforward strategy to addressing the above is to simply remove or minimise solvent usage throughout any designated synthetic routes. One way to achieve a solvent-free, or nearly solvent-free, synthetic route is via the use of solid-state mechanochemical methodologies. Mechanochemistry [1-10] is an emerging solid state methodology involving the use of little or no solvent, with the potential to challenge the current dominance of 'wet' chemical synthesis [1115]. From a purely synthetic point of view, it is clear that complete eradication of solvents might not be entirely beneficial.
Solvents ameliorate reactant interactions, control reaction rates, and aid heat dispersion in exothermic reactions inter alia. Needless to say, solvents are necessary for the extraction, separation, and purification of the final products and/or reaction intermediates [16], which are not always attainable by solvent-free methods [17]. However, the benefits associated with solventfree or nearly solvent-free synthetic routes are becoming increasingly difficult to deny [11-13], even in the eyes of the most sceptical synthetic chemist.

Mechanochemistry is defined as the field of reactions caused by mechanochemical forces (e.g., compression, shear or friction) $[18,19]$. Examples of mechanochemical methods are manual 
and ball-milling grinding techniques [20-22]. Traditional manual mortar and pestle grinding methods are susceptible to variable factors, both human and environmental [23]. In contrast, modern milling technologies address these issues through the use of enclosed solvent-free reaction environments and well-defined experimental conditions throughout the mechanochemical process [24,25]. Amongst the commercially available ball milling designs [23,24], shaker and planetary mills are the most common mechanochemical apparatuses employed in synthetic laboratories [7,16,26,27].

The energy input may be adjusted by modifying parameters including milling time and frequency. Of equal importance in the reaction design is the choice of milling media (i.e., the milling jar loaded with one or more ball bearings). For example, milling balls made from denser materials (e.g., $2.3 \mathrm{~g} \cdot \mathrm{cm}^{-3}$ vs $15.6 \mathrm{~g} \cdot \mathrm{cm}^{-3}$ for Teflon and tungsten carbide, respectively) carry greater kinetic energy during the milling progress. The potential for metal leaching [28], rates of wearing [25], and/or promoting chemical reactions [9,29-33] must also be taken into account when selecting appropriate milling media. In addition to variable mechanical and milling media parameters, an alternative approach to controlling the mechanochemical process is via the use of small amounts of liquid and/or solid additives, termed ion- and liquid-assisted (ILAG) or liquid-assisted grinding (LAG), respectively [34,35]. These techniques, in contrast to "dry" milling, often offer advantages such as shorter reaction times and/or greater product selectivity [36].

In traditional solution-based methods, appropriate selection of solvent, temperature and reaction time will determine whether an intended chemical reaction proceeds, to what extent, and the rate at which it does so. In approaching the same chemical reaction by a mechanochemical route, an alternative set of parameters is fine-tuned to optimise reaction conditions (see Scheme 1). Such differences may have the capacity to create unique reactivity patterns and/or access to otherwise unattainable products [11-15].

Although often considered novel, in its broadest terms, mechanochemistry dates back two millennia [20,37,38]. However, it was not until the 19th century that associations between mechanical forces and chemical reactivity were drawn [39-45], and a century later the currently accepted definition of mechanochemistry was proposed [46]. Since then, and during the last 25 years, mechanochemical methods have been applied to various fields, including catalysis [47], organic synthesis $[5,7,48,49]$, metal-organic frameworks (MOFs) [50,51], coordination [52], organometallic [11], supramolecular [53], environmental [54,55], APIs [56], medicinal [57], nanoscience [15], polymer [58-60] and enzymatic chemistry [61]. The recent advances made in mechanochemistry provide an exciting platform for synthetic chemists in the search of novel outcomes and optimal synthetic routes (see Scheme 2).

\section{Review \\ Main group mechanochemistry}

Whilst mechanochemical studies have become increasingly popular (with recent reviews on mechanochemical synthesis by Rightmire and Hanusa [11], Do and Friščić [12], Hernández and Bolm [13], Wang [14], and James et al. [2]) there are relatively few studies concerning main group elements.

\section{reactants}

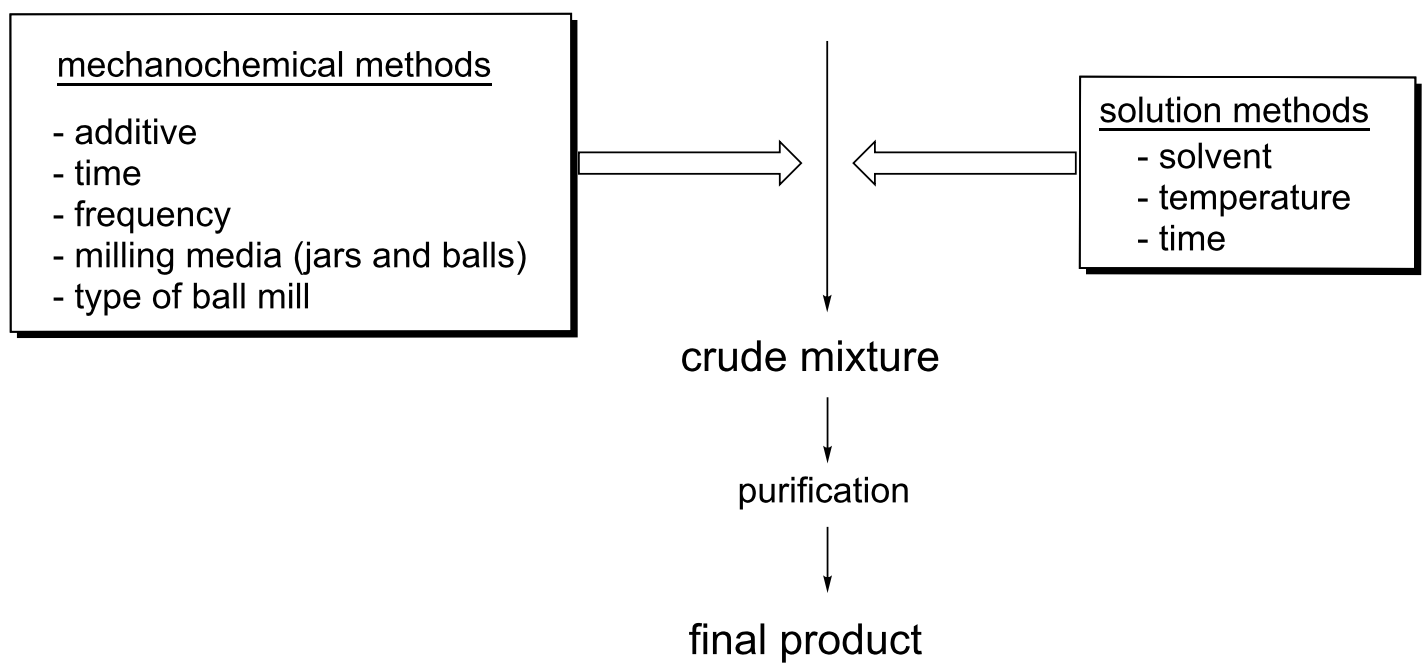



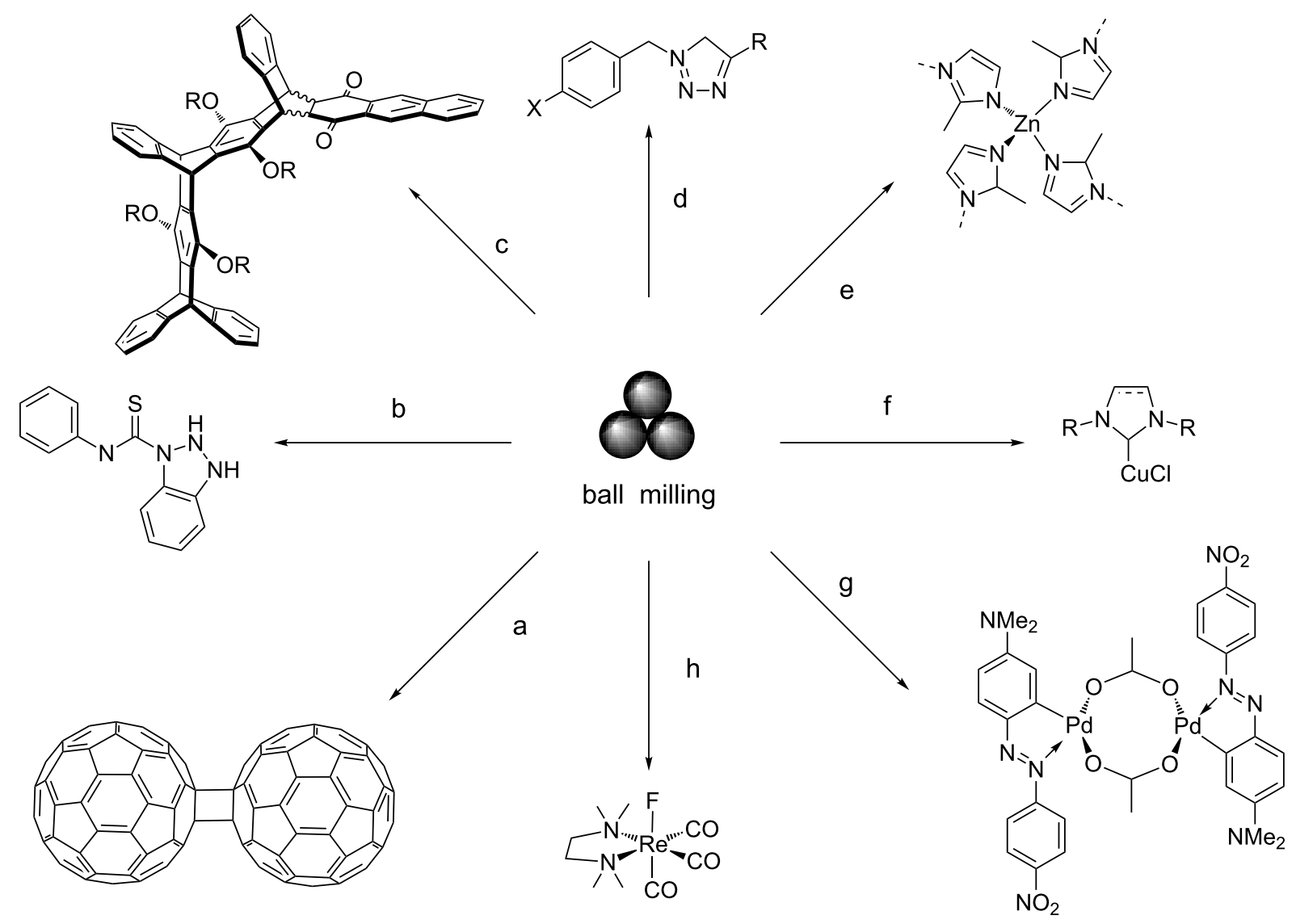

Scheme 2: Examples of mechanochemically produced species (a [48], b [62], c [63], d [64], e [65], f [66], g [67], h [68]). The symbol for mechanochemical reactivity proposed by Hanusa et al. [11] is shown centrally.

The development of new and novel main group frameworks and compounds is pivotal to shaping chemistry as a discipline, in addition to advancing neighbouring fields such as biomedical, materials and engineering sciences [69]. Moreover, main group compounds represent a large proportion of all commercial inorganic chemicals (ammonia, silicones, etc.) [70], and recent advances continue to propel the importance of this field in the 21 st century [71]. For instance, developments in fundamental main group chemistry are pivotal in providing the necessary knowledge and tools for the more sustainable chemical processes, from "blue-skies" to applied research and, eventually, integration into industrial processes.

Herein, we aim to provide an overview of recent advances in this area and an outlook on future directions within the realm of main group molecular systems.

Developments in the area of materials science have already demonstrated benefits of implementing mechanochemical methods [72]. In the context of main group compounds, recent studies have highlighted efficient routes to: (i) alkaline earth carbides and their intercalation compounds, including the first successful synthesis of $\mathrm{Mg}_{2} \mathrm{C}_{3}$ from its elements [73,74]; (ii) nanomaterials, where main group elements act either as a matrix or a dopant, for catalytic applications [75,76]; and (iii) MOFS containing alkaline earth metals $[77,78]$.

Of particular note are the high yielding syntheses of nonsolvated $\mathrm{AlH}_{3}$ from $\mathrm{LiAlH}_{4}$ and $\mathrm{AlCl}_{3}$ under mild conditions, and kinetic studies on the synthesis of alkaline-earth metal amides. These compounds - promising candidates for fuel-cell technologies based on chemically stored hydrogen - highlight the potential of such syntheses in the development of clean energy solutions $[79,80]$.

Within the area of molecular synthesis, the handful of reported examples fall into two general categories, those that provide enhanced synthetic routes, and those that provide novel synthetic outcomes [81]. 


\section{Mechanochemical enhanced synthesis}

Optimising the route to a desired reaction product is a principle priority of synthetic chemists, and ball milling often offers attractive opportunities to do so.

In the field of organometallic chemistry, we highlight the largescale synthesis of $\mathrm{SrCp}_{2}^{\prime}\left(\mathrm{OEt}_{2}\right)\left(\mathrm{Cp}^{\prime}=\mathrm{C}_{5} \mathrm{Me}_{4}(n-\mathrm{Pr})\right)$ (1) [82], an ideal precursor for the chemical vapour deposition (CVD) of strontium-based semiconductors - a key material in memory devices [83]. Previously, this compound could only be obtained in small-scale via salt metathesis reactions due to poor starting material $\left(\mathrm{SrI}_{2}\right.$ and $\left.\mathrm{K}\left[\mathrm{Cp}^{\prime}\right]\right)$ solubility in ether solution. LAG provides a high yielding synthetic methodology circumventing the scalability issues associated with the inefficient diffusion of reactants in large-scale solution-based methods (see Scheme 3).

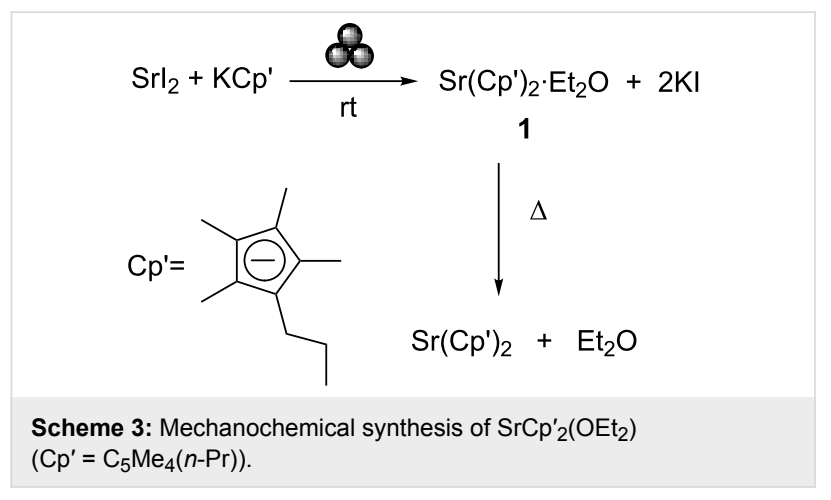

Also noteworthy is the multistep solvent-free mechanochemical route to indium(III) complexes featuring aryl bis(imino)acenaphthene (Ar-BIAN) ligands [84]. Ar-BIAN ligands are versatile $\pi$-acceptors and have been widely em- ployed for catalysis. These ligands are typically synthesised by condensation reactions between acenaphthoquinone and the corresponding aniline derivative under acidic conditions, involving the use of transition-metal templates [85]. The acid-catalysed ball-milling of acenaphthoquinone with aniline derivatives in the presence of an organic catalyst was able to produce the desired Ar-BIAN ligands 2 and $\mathbf{3}$, respectively, in good yields (see Scheme 4). Here, mechanochemistry bypasses the use of templating agent transition metals, shortening the synthetic route and reducing its environmental impact. Their respective indium(III) BIAN complexes $\mathbf{4}$ and $\mathbf{5}$ were also obtained by further milling equimolar quantities of the relevant BIAN ligand ( 2 and 3, respectively) and $\mathrm{InCl}_{3}$. Performing both reactions at $180^{\circ} \mathrm{C}$ in the same reaction vessel without milling lead to thermal decomposition, illustrating the requirement of mechanochemical forces for successful reaction completion. A rare example of a one-pot multistep ball milling reaction is the case of an electron-rich aniline derivative that produced $\mathbf{4}$ in good yield without the need for ligand isolation. Previously reported examples typically employ "preformed" ligands and metal complexes $[68,86]$, raising the orthogonality of multistep mechanochemical synthesis and widening its applicability.

A significant example of the transformative potential of mechanochemistry is its ability to produce metal complexes directly from bulk metal or metal oxides [66]. Within this context, the LAG synthesis of germanes $\left(\mathrm{GeR}_{4}\right)$ directly from germanium metal or germanium dioxide $\left(\mathrm{GeO}_{2}\right)$ was recently reported [87]. Milling of germanium powder or $\mathrm{GeO}_{2}$ with quinone or catechol, respectively, in the presence of a Lewis base under LAG conditions, produced a series of germanium complexes (see Scheme 5). These complexes are inherently

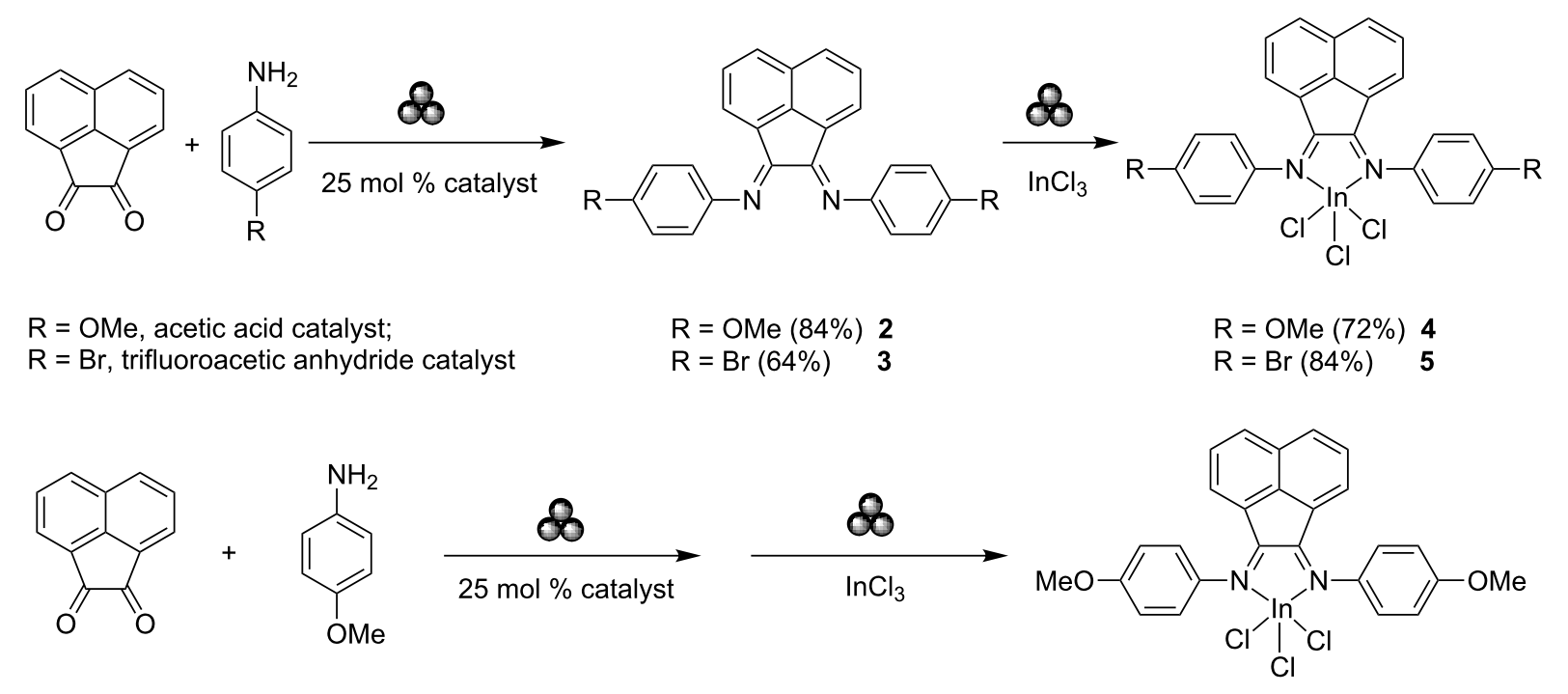

Scheme 4: Mechanochemical synthesis of the Ar-BIAN ligands and indium(III) complexes (top). One-pot synthesis of an indium complex (bottom). 


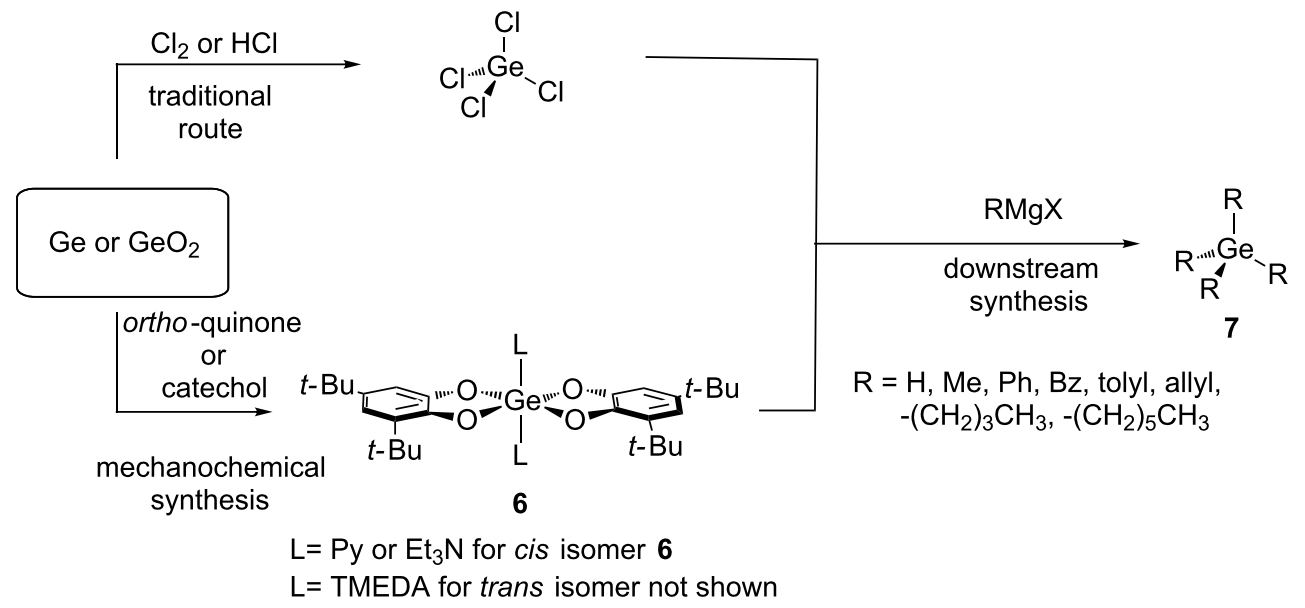

Scheme 5: Synthesis of germanes from germanium $(\mathrm{Ge})$ or germanium oxide $\left(\mathrm{GeO}_{2}\right)$.

versatile, capable of acting as chemical intermediates for the downstream synthesis of germanes 7 , thus providing a sustainable alternative to the use of $\mathrm{GeCl}_{4}$. Notably, this method can generate highly pure $\mathrm{GeH}_{4}$ for CVD applications under room temperature conditions $[88,89]$.

In addition to organometallics, mechanochemistry has emerged as a technique with great promise for the construction of frameworks based on non-carbon backbones [90], such as those of the phosphazane family [91]. The unique chemical versatility of these $\mathrm{P}-\mathrm{N}$ frameworks - provided by the diversity of their topological arrangements - provides potential in numerous applications [92]. However, these species remain typically arduous to synthesize and isolate, since phosphazane arrangements are generally highly air- and moisture-sensitive [93,94], and their halogenated precursors are incompatible with protic solvents. Mechanochemistry therefore offers an elegant synthetic route by circumventing solvent compatibility issues, the tedious processes associated with the use of strict anhydrous solvents, and by minimizing unwanted side-products (see Scheme 6) [95].

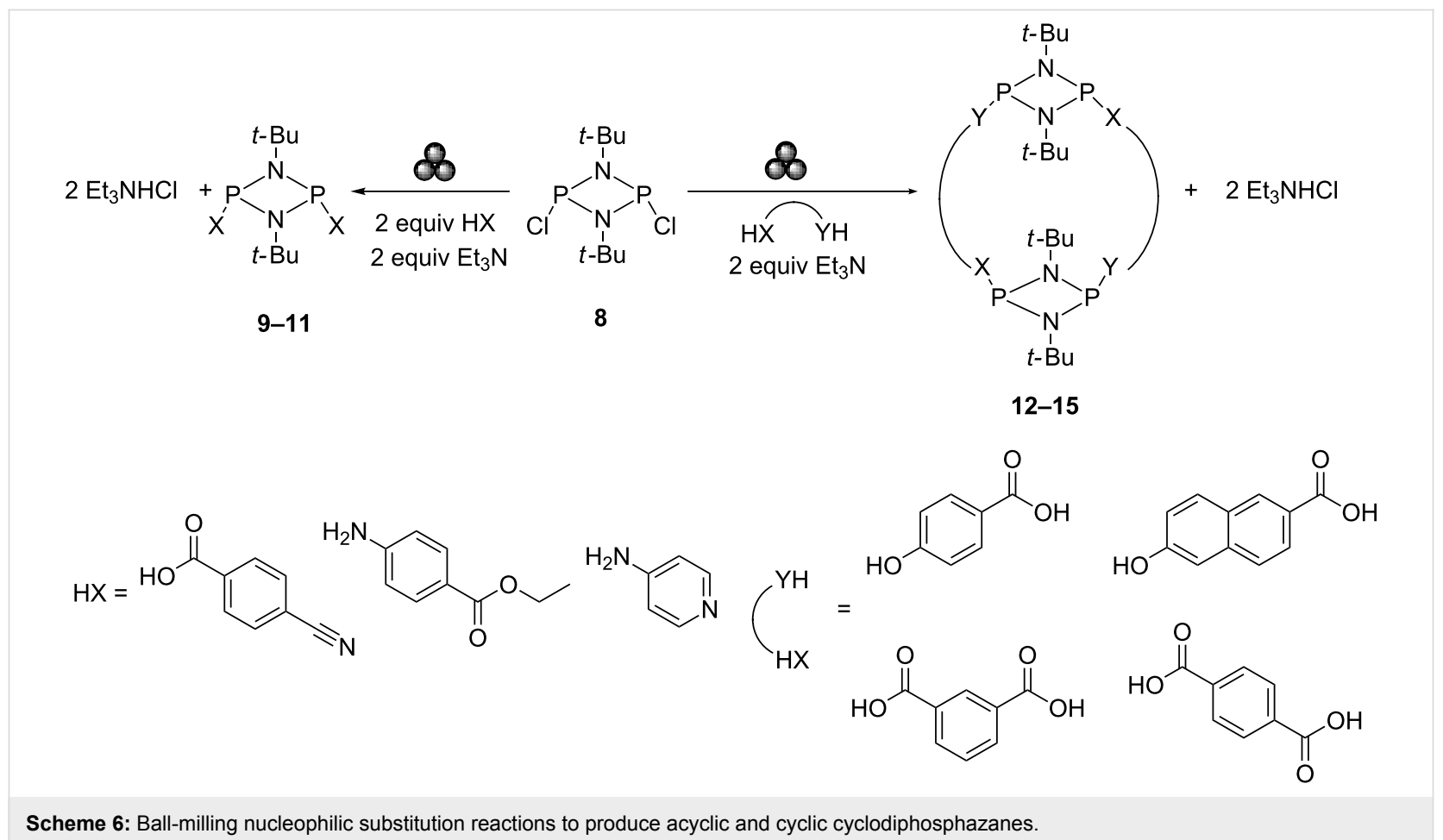




\section{Mechanochemistry picks the lock}

The capacity of mechanochemistry to produce unique reaction outcomes and/or product distributions, compared to those obtained by solution-based methods, is an exciting feat $[62,96]$.

Hanusa et al. reported the successful application of ball-milling for the synthesis of an elusive [97] unsolvated tris(allyl)aluminium complex [98]. Grinding 1,3-bis(trimethylsilyl)allylpotassium salt with $\mathrm{AlX}_{3}(\mathrm{X}=\mathrm{Cl}, \mathrm{Br}, \mathrm{I})$ produced the desired unsolvated product $\mathbf{1 6}$ in high yields and on multigram scales. Remarkably, the synthesis of this long sought-after compound was carried out in a simple set-up, consisting of a round bottom flask loaded with steel ball bearings, connected to a rotatory evaporator as a milling device [99]. Compound $\mathbf{1 6}$ displays a higher reactivity than its solvated counterparts, attributed to the coordinatively unsaturated $\mathrm{Al}$ centre (i.e., three-coordinate $\mathrm{Al}$ ). Only in the absence of solvents can this be achieved.

Similar studies using group 15 halides $\left(\mathrm{AsI}_{3}\right.$ and $\left.\mathrm{SbCl}_{3}\right)$ have shown that selection of solution or mechanochemical conditions influence product stereoisomer distributions. In this case, the mechanochemical route increases the $\mathrm{C}_{1}: \mathrm{C}_{3}$ stereoisomer ratio in complexes $\mathbf{1 7}$ and $\mathbf{1 8}$ for $\mathrm{As}$ and $\mathrm{Sb}$, respectively (see Scheme 7) [100]. The ability to manipulate isomeric distribution outcomes offers obvious advantages in the application of synthetic mechanochemistry to pharmaceutical and catalysis industries.

Returning to phosphazane chemistry, the structure of the $\mathrm{P}-\mathrm{N}$ backbone is controlled by steric factors, a textbook example of which being the adamantoid $\mathrm{P}_{4}(\mathrm{NR})_{6}$ frameworks. These species are synthesised by direct reaction of $\mathrm{PCl}_{3}$ with steri- cally unhindered amines $\mathrm{RNH}_{2}(\mathrm{R}=\mathrm{Me}, \mathrm{Et}, \mathrm{iPr}, \mathrm{Bz})$ [101] or by isomerization of their less thermodynamically-stable macrocyclic $\left[\{\mathrm{P}(\mu-\mathrm{NR})\}_{2}(\mu-\mathrm{NR})\right]_{2}$ counterparts. In the latter, the isopropyl (iPr) substituted macrocycle $\left[\left\{\mathrm{P}(\mu-\mathrm{NiPr})_{2}\right\}_{2}(\mu-\mathrm{NiPr})\right]_{2}$ 19 readily isomerises into the adamantoid framework, $\mathrm{P}_{4}(\mathrm{NiPr})_{6} 20$, upon heating [102]. The non-viability of the tertbutyl $(t-\mathrm{Bu})$ substituted adamantoid framework [103] has been rationalised on steric grounds, due to its highly sterically-encumbered nature [103-105]. ILAG milling of $\left[\left\{\mathrm{P}(\mu-\mathrm{N} t-\mathrm{Bu})_{2}\right\}_{2}(\mu-\mathrm{N} t-\mathrm{Bu})\right]_{2} \mathbf{2 1}$ in the presence of $\mathrm{LiCl}$ readily yielded the adamantoid $\mathrm{P}_{4}(\mathrm{~N} t-\mathrm{Bu})_{6} 22$ after 90 min, in strong contrast to previous efforts involving prolonged heating (24 days at $150{ }^{\circ} \mathrm{C}$ ) or under reflux in a range of solvents with identical amounts of salt additive (see Scheme 8). The ease of this transformation by ball milling illustrates the potential of such approaches towards established chemical syntheses [106].

\section{Conclusion}

The use and study of mechanochemical methods have expanded rapidly over the last two decades, and continues to progress as a well-established area of research within chemical and materials sciences. Whilst the synthetic potential of the ball-milling concept has, in our opinion, become indisputable, advancing from representing an anecdotic alternative to solution-based methods, towards becoming a universally adopted methodology by the main group community remains a considerable challenge [69]. Advancement of our current mechanistic understanding of mechanochemical methods is essential if we are to incorporate it as a mainstream tool for synthetic and materials chemists alike [77,107-111]. Theoretical and systematic studies that elucidate the kinetic and thermodynamic driving forces of mechanochemical reactions are undergoing and will be impera-

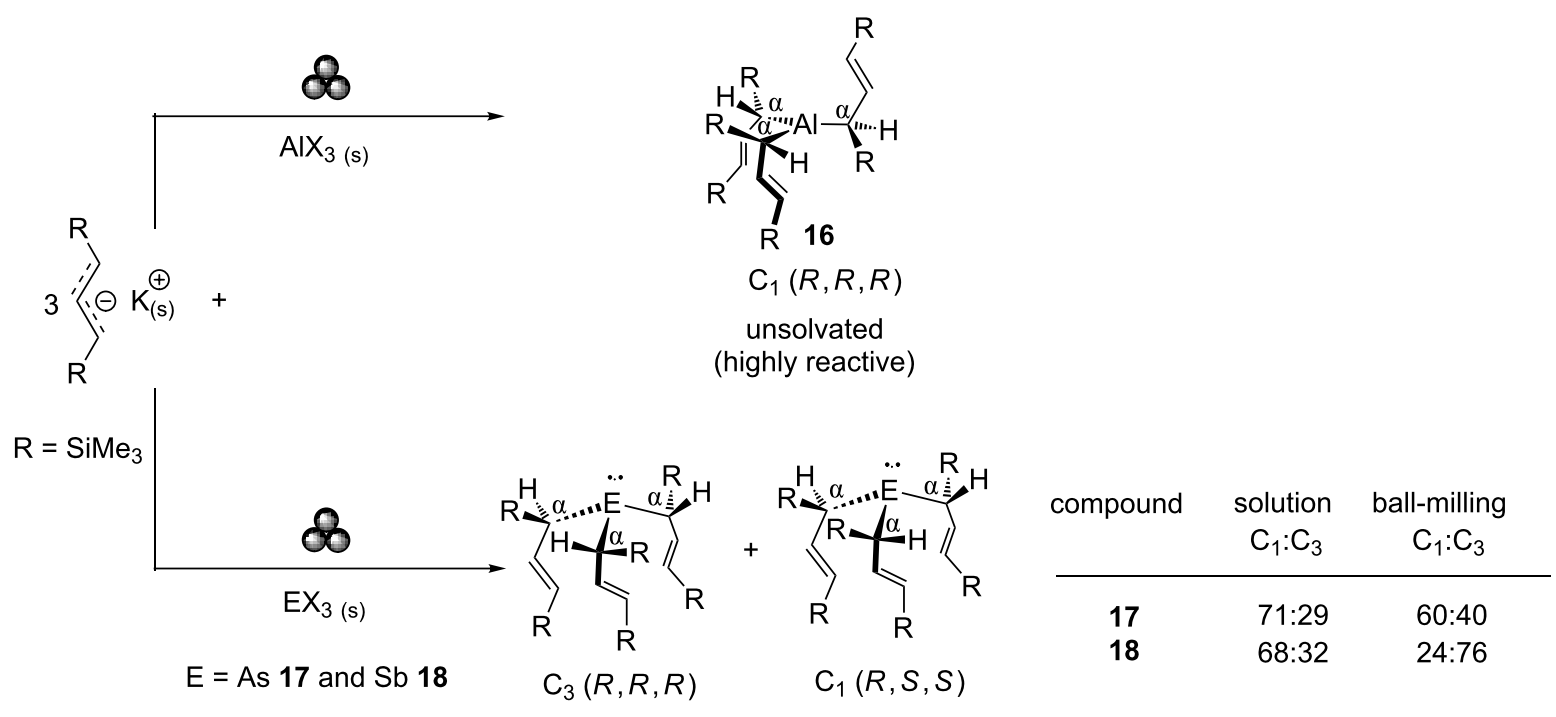




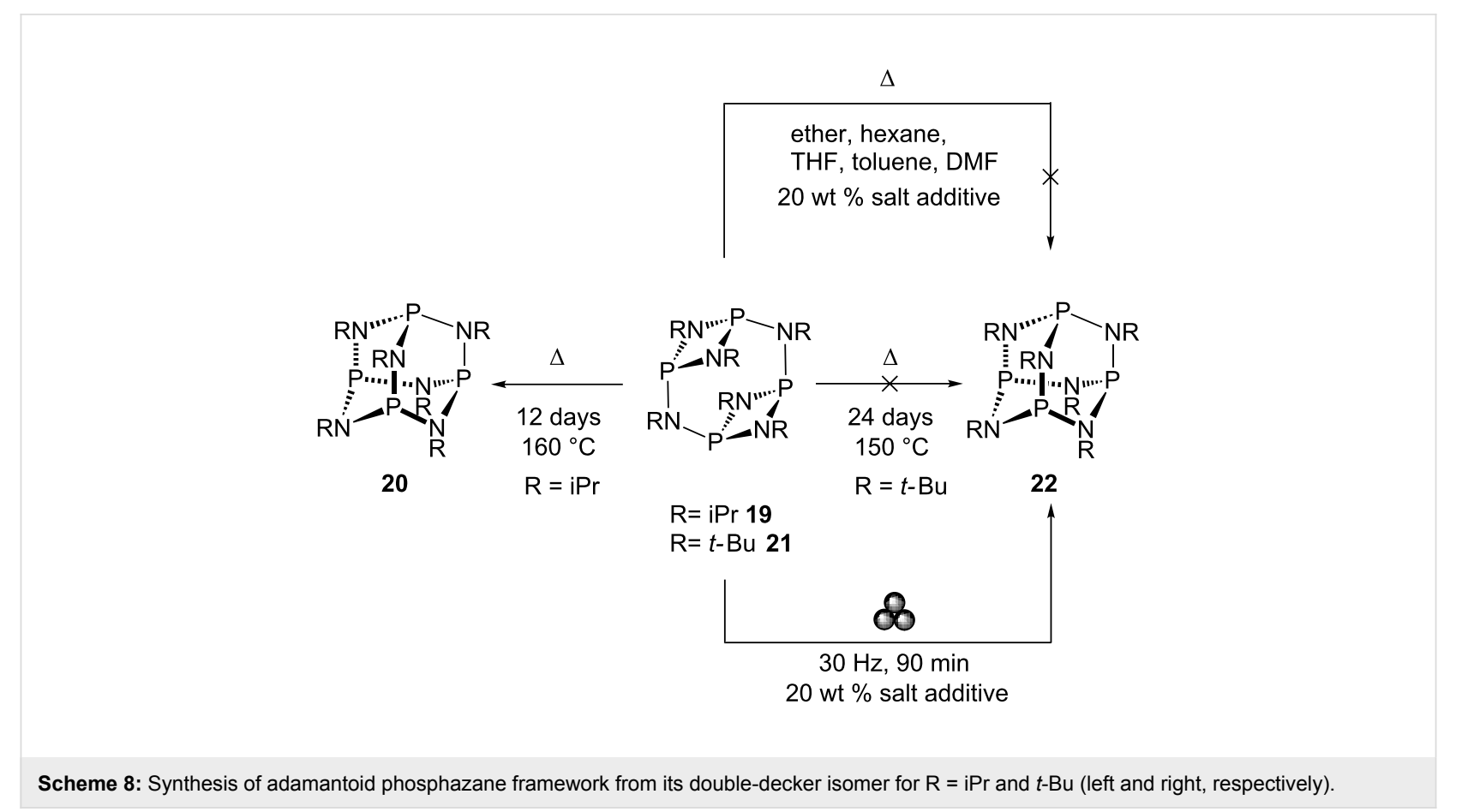

tive to achieving this goal [106,112-114]. Areas in which we anticipate mechanochemistry will show particular strength in: (i) the synthesis of highly air- and moisture-sensitive compounds, since many are incompatible with a wide range of protic solvents [95]; and (ii) the synthesis of unsolvated species, where chemical reactivity might be hindered by the presence of strongly bound solvent molecules within their coordination sphere [98].

In this short review, we have presented basic underlying concepts followed by recent advances and highlights of mechanochemistry in the context of main group synthesis with the hope of encouraging and accelerating the endorsement of mechanochemistry by the main group and wider synthetic communities.

\section{Acknowledgements}

Our work on this field is supported by A*STAR AME IRG (A1783c0003), NTU start-up grant (M4080552) and MOE Tier 1 grant (M4011441).

\section{References}

1. Mechanochemistry is herein considered within the context of transformations conducted by bulk milling or grinding. This area of mechanochemical research is distinct from the popular use of ultrasonic irradiation for transformations of mechanophores embedded in polymer chains or studies of individual molecules using atomic force spectroscopy.
2. James, S. L.; Adams, C. J.; Bolm, C.; Braga, D.; Collier, P.; Friščić, T.; Grepioni, F.; Harris, K. D. M.; Hyett, G.; Jones, W.; Krebs, A.; Mack, J.; Maini, L.; Orpen, A. G.; Parkin, I. P.; Shearouse, W. C.; Steed, J. W.; Waddell, D. C. Chem. Soc. Rev. 2012, 41, 413-447. doi:10.1039/C1CS15171A

3. Boldyreva, E. Chem. Soc. Rev. 2013, 42, 7719-7738. doi:10.1039/c3cs60052a

4. Braga, D.; Maini, L.; Grepioni, F. Chem. Soc. Rev. 2013, 42, 7638-7648. doi:10.1039/c3cs60014a

5. Stolle, A.; Szuppa, T.; Leonhardt, S. E. S.; Ondruschka, B. Chem. Soc. Rev. 2011, 40, 2317-2329. doi:10.1039/c0cs00195c

6. Friščić, T. Chem. Soc. Rev. 2012, 41, 3493-3510. doi:10.1039/c2cs15332g

7. Rodríguez, B.; Bruckmann, A.; Rantanen, T.; Bolm, C. Adv. Synth. Catal. 2007, 349, 2213-2233. doi:10.1002/adsc. 200700252

8. Zhu, S.-E.; Li, F.; Wang, G.-W. Chem. Soc. Rev. 2013, 42, 7535-7570. doi:10.1039/c3cs35494f

9. Chen, L.; Lemma, B. E.; Rich, J. S.; Mack, J. Green Chem. 2014, 16, 1101-1103. doi:10.1039/C3GC41847B

10. Mottillo, C.; Friščić, T. Molecules 2017, 22, 144. doi:10.3390/molecules22010144

11. Rightmire, N. R.; Hanusa, T. P. Dalton Trans. 2016, 45, 2352-2362. doi:10.1039/C5DT03866A

12. Do, J.-L.; Friščić, T. ACS Cent. Sci. 2017, 3, 13-19. doi:10.1021/acscentsci.6b00277

13. Hernández, J. G.; Bolm, C. J. Org. Chem. 2017, 82, 4007-4019. doi:10.1021/acs.joc.6b02887

14. Wang, G.-W. Chem. Soc. Rev. 2013, 42, 7668-7700. doi:10.1039/c3cs35526h 
15. Baláž, P.; Achimovičová, M.; Baláž, M.; Billik, P.; Cherkezova-Zheleva, Z.; Criado, J. M.; Delogu, F.; Dutková, E.; Gaffet, E.; Gotor, F. J.; Kumar, R.; Mitov, I.; Rojac, T.; Senna, M.; Streletskii, A.; Wieczorek-Ciurowa, K. Chem. Soc. Rev. 2013, 42, 7571-7637. doi:10.1039/c3cs35468g

16. Tanaka, K. Solvent-free Organic Synthesis, 2nd ed.; Wiley-VCH: Weinheim, 2009.

17. Friščić, T.; Julien, P. A.; Mottillo, C. Environmentally-Friendly Designs and Syntheses of Metal-Organic Frameworks (MOFs). Green Technologies for the Environment; ACS Symposium Series, Vol. 1186; American Chemical Society, 2014; pp 161-183.

18. Horie, K.; Barón, M.; Fox, R. B.; He, J.; Hess, M.; Kahovec, J.; Kitayama, T.; Kubisa, P.; Maréchal, E.; Mormann, W.; Stepto, R. F. T.; Tabak, D.; Vohlídal, J.; Wilks, E. S.; Work, W. J. Pure Appl. Chem. 2004, 76, 889-906. doi:10.1351/pac200476040889

19. Fernández-Bertran, J. F. Pure Appl. Chem. 1999, 71, 581-586. doi:10.1351/pac199971040581

20. Takacs, L. Chem. Soc. Rev. 2013, 42, 7649-7659. doi:10.1039/c2cs35442j

21. Kipp, S.; Šepelák, V.; Becker, K. D. Chem. Unserer Zeit 2005, 39, 384-392. doi:10.1002/ciuz.200500355

22. Stolle, A.; Schmidt, R.; Jacob, K. Faraday Discuss. 2014, 170 , 267-286. doi:10.1039/C3FD00144J

23. Schmidt, R.; Burmeister, C. F.; Baláž, M.; Kwade, A.; Stolle, A. Org. Process Res. Dev. 2015, 19, 427-436. doi:10.1021/op5003787

24. Baláž, P. Mechanochemistry in Nanoscience and Minerals Engineering; Springer-Verlag: Berlin, 2008.

25. Burmeister, C. F.; Kwade, A. Chem. Soc. Rev. 2013, 42, 7660-7667. doi:10.1039/c3cs35455e

26. Gorrasi, G.; Sorrentino, A. Green Chem. 2015, 17, 2610-2625. doi:10.1039/C5GC00029G

27. Martins, M. A. P.; Frizzo, C. P.; Moreira, D. N.; Buriol, L.; Machado, P. Chem. Rev. 2009, 109, 4140-4182. doi:10.1021/cr9001098

28. Štefanić, G.; Krehula, S.; Štefanić, I. Chem. Commun. 2013, 49, 9245-9247. doi:10.1039/c3cc44803g

29. Rak, M. J.; Saadé, N. K.; Friščić, T.; Moores, A. Green Chem. 2014, 16, 86-89. doi:10.1039/C3GC41827H

30. Fulmer, D. A.; Shearouse, W. C.; Medonza, S. T.; Mack, J. Green Chem. 2009, 11, 1821-1825. doi:10.1039/b915669k

31. Cook, T. L.; Walker, J. A., Jr.; Mack, J. Green Chem. 2013, 15, 617-619. doi:10.1039/c3gc36720g

32. Tan, D.; Štrukil, V.; Mottillo, C.; Friščić, T. Chem. Commun. 2014, 50, 5248-5250. doi:10.1039/C3CC47905F

33. Sawama, Y.; Kawajiri, T.; Niikawa, M.; Goto, R.; Yabe, Y.; Takahashi, T.; Marumoto, T.; Itoh, M.; Kimura, Y.; Monguchi, Y.; Kondo, S.-i.; Sajiki, H. ChemSusChem 2015, 8, 3773-3776. doi:10.1002/cssc.201501019

34. Friščić, T.; Childs, S. L.; Rizvi, S. A. A.; Jones, W. CrystEngComm 2009, 11, 418-426. doi:10.1039/B815174A

35. Friščić, T.; Reid, D. G.; Halasz, I.; Stein, R. S.; Dinnebier, R. E.; Duer, M. J. Angew. Chem., Int. Ed. 2010, 49, 712-715. doi:10.1002/anie.200906583

36. Bowmaker, G. A. Chem. Commun. 2013, 49, 334-348. doi:10.1039/C2CC35694E

37. Theophrastus wrote „On Stones” ca. 315 B.C. This book contains references to the reduction of cinnabar (a mercury ore) to mercury metal by grinding the ore in a copper mortar and pestle.

38. Takacs, L. JOM 2000, 52, 12-13. doi:10.1007/s11837-000-0106-0

39. Faraday, M. Q. J. Sci., Lit., Arts 1820, 8, 374-376.

40. Lea, M. C. Br. J. Photogr. 1866, 13, 84.
41. Lea, M. C. Am. J. Sci. 1893, 46, 413-420. doi:10.2475/ajs.s3-46.276.413

42. Ling, A. R.; Baker, J. L. J. Chem. Soc., Trans. 1893, 63, 1314. doi:10.1039/CT8936301314

43. Takacs, L. J. Therm. Anal. Calorim. 2007, 90, 81-84. doi:10.1007/s10973-007-8479-8

44. The term "mechanochemistry" was first introduced by Wilhelm Ostwald in the Textbook of General Chemistry in 1891, where mechanochemistry was considered as a part of physical chemistry such as thermochemistry, electrochemistry.

45. Ostwald, W. Handbuch der Allgemeinen Chemie; Akademische Verlagsgesellschaft mbH: Leipzig, 1919; Vol. 1.

46. Heinicke, G. Tribochemistry; Akademie Verlag: Berlin, 1984.

47. Bruckmann, A.; Krebs, A.; Bolm, C. Green Chem. 2008, 10, 1131-1141. doi:10.1039/b812536h

48. Wang, G.-W.; Komatsu, K.; Murata, Y.; Shiro, M. Nature 1997, 387, 583-586. doi:10.1038/42439

49. Hernández, J. G.; Friščić, T. Tetrahedron Lett. 2015, 56, 4253-4265. doi:10.1016/j.tetlet.2015.03.135

50. Friščić, T. Metal-Organic Frameworks: Mechanochemical Synthesis Strategies. Encyclopedia of Inorganic and Bioinorganic Chemistry; Wiley: Chichester, 2014; pp 1-19. doi:10.1002/9781119951438.eibc2202

51. Lazuen-Garay, A.; Pichon, A.; James, S. L. Chem. Soc. Rev. 2007, 36, 846-855. doi:10.1039/b600363j

52. Thabet, S. K.; Tayim, H. A.; Karkanawi, M. U. Inorg. Nucl. Chem. Lett. 1972, 8, 211-213. doi:10.1016/0020-1650(72)80114-4

53. Hsu, C.-C.; Chen, N.-C.; Lai, C.-C.; Liu, Y.-H.; Peng, S.-M.; Chiu, S.-H. Angew. Chem., Int. Ed. 2008, 47, 7475-7478. doi:10.1002/anie.200803056

54. Rowlands, S. A.; Hall, A. K.; McCormick, P. G.; Street, R.; Hart, R. J.; Ebell, G. F.; Donecker, P. Nature 1994, 367, 223. doi:10.1038/367223a0

55. Nomura, Y.; Nakai, S.; Hosomi, M. Environ. Sci. Technol. 2005, 39, 3799-3804. doi:10.1021/es049446w

56. Jones, W.; Eddleston, M. D. Faraday Discuss. 2014, 170, 9-34. doi:10.1039/C4FD00162A

57. Tan, D.; Loots, L.; Friščić, T. Chem. Commun. 2016, 52, 7760-7781. doi:10.1039/C6CC02015A

58. Ravnsbæk, J. B.; Swager, T. M. ACS Macro Lett. 2014, 3, 305-309. doi: $10.1021 / \mathrm{mz} 500098 \mathrm{r}$

59. Grätz, S.; Borchardt, L. RSC Adv. 2016, 6, 64799-64802. doi:10.1039/C6RA15677K

60. Ohn, N.; Shin, J.; Kim, S. S.; Kim, J. G. ChemSusChem 2017, in press. doi:10.1002/cssc.201700873

61. Hernández, J. G.; Ardila-Fierro, K. J.; Crawford, D.; James, S. L.; Bolm, C. Green Chem. 2017, 19, 2620-2625. doi:10.1039/C7GC00615B

62. Štrukil, V.; Gracin, D.; Magdysyuk, O. V.; Dinnebier, R. E.; Friščić, T. Angew. Chem., Int. Ed. 2015, 54, 8440-8443. doi:10.1002/anie.201502026

63. Zhao, Y.; Rocha, S. V.; Swager, T. M. J. Am. Chem. Soc. 2016, 138, 13834-13837. doi:10.1021/jacs.6b09011

64. Chen, L.; Bovee, M. O.; Lemma, B. E.; Keithley, K. S. M.; Pilson, S. L.; Coleman, M. G.; Mack, J. Angew. Chem., Int. Ed. 2015, 54, 11084-11087. doi:10.1002/anie.201504236

65. Katsenis, A. D.; Puškarić, A.; Štrukil, V.; Mottillo, C.; Julien, P. A.; Užarević, K.; Pham, M.-H.; Do, T.-O.; Kimber, S. A. J.; Lazić, P.; Magdysyuk, V. O.; Dinnebier, R. E.; Halasz, I.; Friščić, T. Nat. Commun. 2015, 6, No. 6662. doi:10.1038/ncomms7662 
66. Beillard, A.; Metro, T.-X.; Bantreil, X.; Martinez, J.; Lamaty, F. Chem. Sci. 2017, 8, 1086-1089. doi:10.1039/C6SC03182J

67. Juribašić, M.; Užarević, K.; Gracin, D.; Ćurić, M. Chem. Commun. 2014, 50, 10287-10290. doi:10.1039/C4CC04423A

68. Hernández, J. G.; Butler, I. S.; Friščić, T. Chem. Sci. 2014, 5, 3576-3582. doi:10.1039/C4SC01252F

69. Chivers, T. Comments Inorg. Chem. 2009, 30, 131-176. doi:10.1080/02603590903385752

70. Thomson, R., Ed. Industrial Inorganic Chemicals: Production and Uses; The Royal Society of Chemistry: Cambridge, 1995.

71. Aldridge, S.; Jones, C. Chem. Soc. Rev. 2016, 45, 763-764. doi:10.1039/C6CS90014C

72. Xu, C.; De, S.; Balu, A. M.; Ojeda, M.; Luque, R. Chem. Commun. 2015, 51, 6698-6713. doi:10.1039/C4CC09876E

73. The alkaline earth carbide $\mathrm{CaC}_{2}$ is an industrial source of acetylene, however, non-mechanochemical methods of its production were unsuitable on a commercial scale due to the requirement of maintaining a very high temperature, oxygen-free atmosphere, and use of hydrogen cyanide gas as reagent. Hence ball milling provides a more efficient and green route to these molecular species.

74. Hick, S. M.; Griebel, C.; Blair, R. G. Inorg. Chem. 2009, 48, 2333-2338. doi:10.1021/ic8022437

75. Sun, J.; Zheng, G.; Lee, H.-W.; Liu, N.; Wang, H.; Yao, H.; Yang, W.; Cui, Y. Nano Lett. 2014, 14, 4573-4580. doi:10.1021/nl501617j

76. Kim, M.-J.; Jeon, I.-Y.; Seo, J.-M.; Dai, L.; Baek, J.-B. ACS Nano 2014, 8, 2820-2825. doi:10.1021/nn4066395

77. Al-Terkawi, A.-A.; Scholz, G.; Emmerling, F.; Kemnitz, E. Cryst. Growth Des. 2016, 16, 1923-1933. doi:10.1021/acs.cgd.5b01457

78. Al-Terkawi, A.-A.; Scholz, G.; Buzanich, A. G.; Reinsch, S.; Emmerling, F.; Kemnitz, E. Dalton Trans. 2017, 46, 6003-6012. doi:10.1039/C7DT00734E

79. Gupta, S.; Kobayashi, T.; Hlova, I. Z.; Goldston, J. F.; Pruski, M.; Pecharsky, V. K. Green Chem. 2014, 16, 4378-4388. doi:10.1039/C4GC00998C

80. Garroni, S.; Takacs, L.; Leng, H.; Delogu, F. Chem. Phys. Lett. 2014, 608, 80-83. doi:10.1016/j.cplett.2014.05.071

81. To the best of our knowledge, there are no published reports of solvent removal being detrimental throughout main group molecular synthesis. For published results in the area of organometallic synthesis please see section 3.2 in ref [11].

82. Peters, D. W.; Blair, R. G. Faraday Discuss. 2014, 170, 83-91. doi:10.1039/C3FD00157A

83. Warusawithana, M. P.; Cen, C.; Sleasman, C. R.; Woicik, J. C.; Li, Y.; Kourkoutis, L. F.; Klug, J. A.; Li, H.; Ryan, P.; Wang, L.-P.; Bedzyk, M.; Muller, D. A.; Chen, L.-Q.; Levy, J.; Schlom, D. G. Science 2009, 324, 367-370. doi:10.1126/science.1169678

84. Wang, J.; Ganguly, R.; Yongxin, L.; Díaz, J.; Soo, H. S.; García, F. Dalton Trans. 2016, 45, 7941-7946. doi:10.1039/C6DT00978F

85. Ragaini, F.; Cenini, S.; Tollari, S.; Tummolillo, G.; Beltrami, R. Organometallics 1999, 18, 928-942. doi:10.1021/om980843n

86. Chow, E. H. H.; Strobridge, F. C.; Friščić, T. Chem. Commun. 2010, 46, 6368-6370. doi:10.1039/c0cc01337d

87. Glavinović, M.; Krause,, M.; Yang,, L.; McLeod, J. A.; Liu, L.; Baines, K. M.; Friščić, T.; Lumb, J.-P. Sci. Adv. 2017, 3, e1700149. doi:10.1126/sciadv.1700149

88. Rusotti, R. Methods of synthesis of gaseous germane. U.S. Patent US 4,668,502, May 26, 1987.

89. Amadoruge, M. L.; Weinert, C. S. Chem. Rev. 2008, 108, 4253-4294. doi:10.1021/cr800197r
90. Hardacre, C.; Huang, H.; James, S. L.; Migaud, M. E.; Norman, S. E.; Pitner, W. R. Chem. Commun. 2011, 47, 5846-5848. doi:10.1039/c1cc11025j

91. In this context, the term 'phosphazane' refers to phosphorus(III) derivatives unless otherwise stated.

92. Balakrishna, M. S. Dalton Trans. 2016, 45, 12252-12282. doi:10.1039/C6DT01121G

93. Scherer, O. J.; Anselmann, R.; Paine, R. T.; Karthikeyan, S. Tervalent Phosphorus-Nitrogen Ring Compounds. Inorganic Syntheses; John Wiley \& Sons, Inc., 2007; Vol. 25, pp 7-12.

94. Shi, X. Y.; Liang, R. Z.; Martin, K. A.; Weston, N.; Gonzalez-Calera, S.; Ganguly, R.; Li, Y.; Lu, Y.; Ribeiro, A. J. M.; Ramos, M. J.; Fernandes, P. A.; García, F. Inorg. Chem. 2015, 54, 6423-6432. doi:10.1021/acs.inorgchem.5b00735

95. Sim, Y.; Shi, Y. X.; Ganguly, R.; Li, Y.; García, F. Chem. - Eur. J. 2017, 23, 11279-11285. doi:10.1002/chem.201701619

96. Katritzky, A. R.; Witek, R. M.; Rodriguez-Garcia, V.; Mohapatra, P. P.; Rogers, J. W.; Cusido, J.; Abdel-Fattah, A. A. A.; Steel, P. J. J. Org. Chem. 2005, 70, 7866-7881. doi:10.1021/jo050670t

97. Grignard, V.; Jenkins, R. L. Bull. Soc. Chim. Fr. 1925, 37, 1376-1385.

98. Rightmire, N. R.; Hanusa, T. P.; Rheingold, A. L. Organometallics 2014, 33, 5952-5955. doi:10.1021/om5009204

99. Higher yielding and higher scales were also possible using an IKKA tube dispenser ( $15 \mathrm{~min}$ reaction time with $85 \%$ yield) and planetary ball mill ( $5 \mathrm{~min}$ at $600 \mathrm{rpm}$ with $88 \%$ yield) on a multigram scale.

100. Rightmire, N. R.; Bruns, D. L.; Hanusa, T. P.; Brennessel, W. W. Organometallics 2016, 35, 1698-1706. doi:10.1021/acs.organomet.6b00151

101. Hill, T. G.; Haltiwanger, R. C.; Thompson, M. L.; Katz, S. A.; Norman, A. D. Inorg. Chem. 1994, 33, 1770-1777. doi:10.1021/ic00087a009

102.Scherer, O. J.; Andres, K.; Krüger, C.; Tsay, Y.-H.; Wolmerhäser, G. Angew. Chem., Int. Ed. Engl. 1980, 19, 571-572. doi:10.1002/anie.198005711

103.Brask, J. K.; Chivers, T.; Krahn, M. L.; Parvez, M. Inorg. Chem. 1999, 38, 290-295. doi:10.1021/ic980117c

104.Bashall, A.; Doyle, E. L.; Garcia, F.; Lawson, G. T.; Linton, D. J.; Moncrieff, D.; McPartlin, M.; Woods, A. D.; Wright, D. S. Chem. - Eur. J. 2002, 8, 5723-5731. doi:10.1002/1521-3765(20021216)8:24<5723::AID-CHEM5723>3.0.C O;2-D

105.Shi, Y. X.; Liang, R. Z.; Martin, K. A.; Star, D. G.; Díaz, J.; Li, X. Y.; Ganguly, R.; García, F. Chem. Commun. 2015, 51, 16468-16471. doi:10.1039/C5CC06034F

106.Shi, Y. X.; Xu, K.; Clegg, J. K.; Ganguly, R.; Hirao, H.; Friščić, T.; García, F. Angew. Chem., Int. Ed. 2016, 55, 12736-12740. doi:10.1002/anie.201605936

107. Michalchuk, A. A. L.; Tumanov, I. A.; Drebushchak, V. A.; Boldyreva, E. V. Faraday Discuss. 2014, 170, 311-335. doi:10.1039/C3FD00150D

108. Boldyreva, E. Curr. Pharm. Des. 2016, 22, 4981-5000. doi:10.2174/1381612822666160804093120

109. Tumanov, I. A.; Michalchuk, A. A. L.; Politov, A. A.; Boldyreva, E. V.; Boldyrev, V. V. CrystEngComm 2017, 19, 2830-2835. doi:10.1039/C7CE00517B

110. Michalchuk, A. A. L.; Tumanov, I. A.; Sumit, K.; Kimber, S. A. J.; Pulham, C. R.; Boldireva, E. V. Adv. Sci. 2017, 1700132. doi:10.1002/advs.201700132

111. Andersen, J. M.; Mack,, J. Chem. Sci. 2017, 8, 5447-5453. doi:10.1039/C7SC00538E 
112.Belenguer, A. M.; Friščić, T.; Day, G. M.; Sanders, J. K. M. Chem. Sci. 2011, 2, 696-700. doi:10.1039/c0sc00533a

113.Bygrave, P. J.; Case, D. H.; Day, G. M. Faraday Discuss. 2014, 170 41-57. doi:10.1039/C3FD00162H

114.Belenguer, A. M.; Lampronti, G. I.; Cruz-Cabeza, A. J.; Hunter, C. A.; Sanders, J. K. M. Chem. Sci. 2016, 7, 6617-6627.

doi:10.1039/C6SC03457H

\section{License and Terms}

This is an Open Access article under the terms of the Creative Commons Attribution License

(http://creativecommons.org/licenses/by/4.0), which permits unrestricted use, distribution, and reproduction in any medium, provided the original work is properly cited.

The license is subject to the Beilstein Journal of Organic Chemistry terms and conditions:

(http://www.beilstein-journals.org/bjoc)

The definitive version of this article is the electronic one which can be found at: doi:10.3762/bjoc. 13.204 